\title{
Soft Tissue Squamous Cell Carcinoma in Chest Wall with an Incomplete Border Sign
}

\author{
Tatsuo Kimura ${ }^{\text {a, }}$, Shinzoh Kudoha, Yoshihiro Tochino ${ }^{a}$, Toyoki Kodama ${ }^{\text {a }}$, Saeko Matsumura ${ }^{\text {a }}$ \\ Kazuto Hirata ${ }^{a}$
}

\begin{abstract}
Squamous cell carcinoma (SCC) of the soft tissue in chest wall from an unknown primary site is extremely rare. We report a case with soft tissue metastasis with histology of SCC to chest wall with an incomplete border sign in chest radiography. Chest radiography revealed a radio-opaque lesion in the left lung field. Computed tomography (CT) detected the mass under the musculus pectoralis major invading the left 2 nd - 6 th ribs with increase in pleural thickness. Careful radiological observations, including chest radiography and CT, may aid the diagnosis and planning of treatments.
\end{abstract}

Keywords: Chest wall; Incomplete border sign; Unknown primary; Squamous cell carcinoma

\section{Introduction}

Squamous cell carcinoma (SCC) of the soft tissue in chest wall from unknown primary site is extremely rare. A review of 118 cases of metastatic tumors to soft tissue identified only one case of SCC metastasized in chest wall from unknown primary site [1]. We report a case with metastatic tumors to soft tissue in chest wall with unique radiological observation of an incomplete border sign. To my knowledge, this sign on radiographs of the abdominal and chest wall masses was

Manuscript accepted for publication December 27, 2010

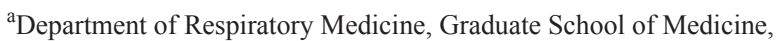
Osaka City University, Osaka, Japan

${ }^{\mathrm{b}}$ Corresponding author: Department of Respiratory Medicine, Graduate School of Medicine, Osaka City University, 1-4-3, Asahimachi, Abeno-ku, Osaka, 545-8585, Japan. Email: kimutats@med.osaka-cu. ac.jp

doi: $10.4021 / \mathrm{jmc} 115 \mathrm{w}$ first described by Mendelson in 1964 [2]. Nevertheless, even today, it may be useful to be aware of this sign that helps to further define opacity evident on conventional radiographs.

\section{Case Report}

A 74-year-old man presented with acute chest pain with enlarged left chest muscles. Postero-anterior view of chest radiography revealed a radio-opaque lesion in the left lung field by a sharp, well-defined edge on the left lateral side (Fig. 1a). An ill-defined edge on the other side along at least one portion of its contour blends with the chest wall. Oblique view showed an extra pleural mass with a sharp margin (Fig. 1b). Computed tomography (CT) detected the mass under the musculus pectoralis major invading the left 2 nd - 6th ribs with increase in pleural thickness (Fig. 2). Transbronchial biopsy from Lt B4b revealed inflammatory cell infiltration with no tumor involvement. Ultrasound-guided needle biopsy confirmed the diagnosis of squamous cell carcinoma (SCC) (Fig. 3) with immunohistochemical findings negative for TTF-1 and plus-minus for Cytokeratin 5/6. Neither inspection of the skin nor whole-body CT scan could detect any primary lesions. The site of origin was unknown. The patient received a weekly chemotherapy regimen of CBDCA
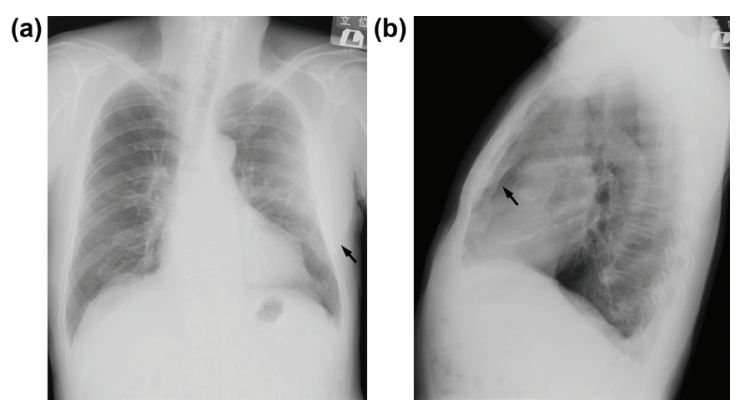

Figure 1. (a) Posteroanterior view of chest radiography revealed a radio-opaque lesion in the left lung field by a sharp, well-defined edge on the left lateral side (arrow). An ill-defined edge on the other side along at least one portion of its contour blends with the chest wall. (b) Oblique view showed an extra pleural mass with a sharp margin (arrow). 
(a)

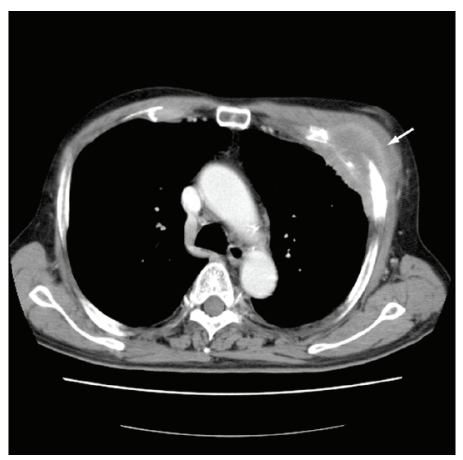

(b)

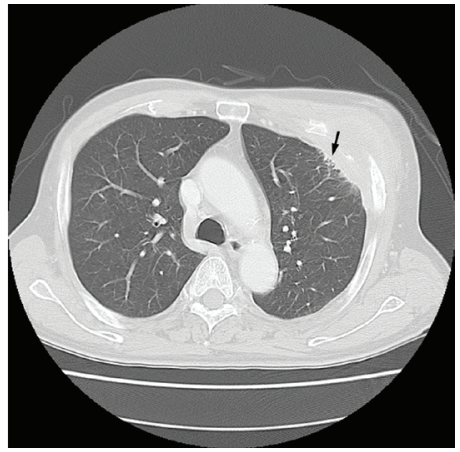

Figure 2. (a) Contrast-enhanced axial CT image showed a mass under the musculus pectoralis major invading the left third rib (arrow). (b) The same level of high-resolution CT $(3 \mathrm{~mm})$ revealed focal thickness of the pleura and interstitial reactions (arrow).

$(A U C=2)$ plus paclitaxel $\left(40 \mathrm{mg} / \mathrm{m}^{2}\right)$ and oblique approach of $60 \mathrm{~Gy}$ external radiotherapy. There was marked shrinkage of the tumor mass on CT scan and no sign of recurrence for 8 months.

\section{Discussion}

SCC of the soft tissue in chest wall from unknown primary site is extremely rare. The assessment of chest radiological observations is important in diagnosing and planning therapy in patients with chest-wall abnormalities. We report a case with metastatic tumors to soft tissue in chest wall with unique radiological observation of the incomplete border sign. To my knowledge, this sign on radiographs of the abdominal wall masses such as inguinal and femoral hernias, and chest wall masses such as metastatic prostate carcinoma, lipoma, and skin grafts, was first described by Mendelson in 1964 [2]. This sign of extra-pleural masses of a chondrosarcoma of the rib was described by Ellis in 1977 [3]. Recently, this abdominal incomplete border sign of an umbilical lipoma was reported by Catalano in 2002 [4]. The classical

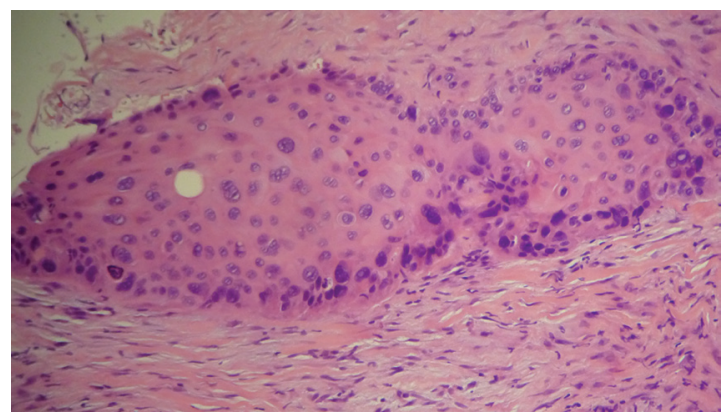

Figure 3. The histological finding obtained from ultrasoundguided needle biopsy confirmed the diagnosis of squamous cell carcinoma (hematoxiline and eosine). example of this sign is the female breasts, which on the posteroanterior view is sharply defined inferiorly but indistinct superiorly where it blends with the chest wall. Indeed, the female breasts are readily apparent on physical examination. In contrast, the extra-pleural sign is a conventional radiographic finding that can be visualized on chest radiograph. Expanding lesions of structures in the chest wall, which is convex towards the lung, give rise to this sign, as a moundlike protrusion arising from the chest wall, border at its base than in height, and having obtuse angles with chest wall [5]. As is evident, chest wall masses can arise from any of these component tissues, and may be located in the subcutaneous fat or within the chest wall muscles, or they may insinuate through the ribs to become subpleural or intrathoracic masses. These findings demonstrate the incomplete border sign or the extra-pleural sign on the chest radiograph.

In our case, the chest radiography of posteroanterior view revealed a radio-opaque lesion in the left lung field. The soft-tissue mass was characterized by a sharp, well-defined edge on the left lateral side. The ill-defined edge on the other side along at least one portion of its contour blends with the chest wall. Oblique view showed an extra pleural mass with a sharp margin. The incompleteness of the border of the mass was due to the fact that the site of anchorage of the mass abutted the musculus pectoralis, affording no radiographic contrast. Clearly, recognition of a mass arising from the chest wall is not difficult on physical examination. It is useful to be aware of the relationship existing between the mass and the X-ray beam on conventional radiographs.

The clinical distinction between a metastatic carcinoma to soft tissue and a primary soft-tissue sarcoma is critical because treatment and prognosis are markedly different. Malignant chest wall tumors are a heterogeneous group of tumors including invasive tumors, primary tumors, and metastatic tumors. Invasive chest wall tumors are relatively common, and the majority of the tumors in this group originated from the lung, breast, soft-tissue tumors, and skeletal tumors [6]. 
Primary chest wall tumors account for less than $1 \%$ to $2 \%$ of all primary tumors [7]. These tumors develop in the bone, skins, and soft tissues of the thoracic cage. Metastatic chest wall tumors presenting as soft tissue masses are relatively rare, and the majority of the tumors reported in this group originated from the lung, breast, and head and neck tumors [1]. In our case, fluorodeoxyglucose positron emission tomography was not performed, however, neither inspection of skin nor whole-body CT scan could detect any primary lesions. The site of origin was unknown. Squamous cells may arise from luminal epithelial cells, myoepithelial cells, or ductal metaplasia [8].

A remarkable treatment response was seen in our patient, who received platinum-based chemotherapy and radiotherapy. The therapeutic strategy for metastatic cancer of unknown primary site should always be individualized according to the clinical subset [9]. Loco-regional management is the primary recommended treatment. The treatment of our type of patient should follow guidelines for locally advanced head and neck cancer or non-small cell lung cancer. A multimodal treatment approach may improve the prognosis of this rare disease.

\section{References}

1. Plaza JA, Perez-Montiel D, Mayerson J, Morrison C, Suster S. Metastases to soft tissue: a review of 118 cases over a 30-year period. Cancer 2008;112(1):193-203.

2. Mendelson E. Abdominal Wall Masses: The Usefulness of the Incomplete Border Sign. Radiol Clin North Am 1964;2:161-166.

3. Ellis R. Incomplete border sign of extrapleural masses. JAMA 1977;237(25):2748.

4. Catalano O. The incomplete border sign. Radiology 2002;225(1):129-130.

5. Rogers L, Norris M. Bone Tumors and Rlated Conditions, in: J. Juhl, A. Crummy, J. Kuhlman, (Eds.), Essentials of Radiologic Imaging, Lippincott-Raven, Philadelphia, 1998; 129-172.

6. Thomas-de-Montpreville V, Chapelier A, Fadel E, Mussot S, Dulmet E, Dartevelle P. Chest wall resection for invasive lung carcinoma, soft tissue sarcoma, and other types of malignancy. Pathologic aspects in a series of 107 patients. Ann Diagn Pathol 2004;8(4):198-206.

7. Athanassiadi K, Kalavrouziotis G, Rondogianni D, Loutsidis A, Hatzimichalis A, Bellenis I. Primary chest wall tumors: early and long-term results of surgical treatment. Eur J Cardiothorac Surg 2001;19(5):589-593.

8. Dejager D, Redlich PN, Dayer AM, Davis HL, Komorowski RA. Primary squamous cell carcinoma of the breast: sensitivity to cisplatinum-based chemotherapy. J Surg Oncol 1995;59(3):199-203.

9. Pavlidis N, Briasoulis E, Hainsworth J, Greco FA. Diagnostic and therapeutic management of cancer of an unknown primary. Eur J Cancer 2003;39(14):1990-2005. 